\title{
PERSON-CENTERED INTEGRATIVE DIAGNOSIS: CONCEPTS AND PROCEDURES
}

\author{
Ihsan M. Salloum, MD, MPH ${ }^{a}$ and Juan E. Mezzich, MD, MA, MSc, PhD ${ }^{b}$
}

\section{ABSTRACT}

The person-centered integrative diagnosis (PID) is a model that aims at putting into practice the vision of person-centered medicine affirming the whole person of the patient in context as the center of clinical care and health promotion at the individual and community levels. The PID is a novel model of conceptualizing the process and formulation of clinical diagnosis. The PID presents a paradigm shift with a broader and deeper notion of diagnosis, beyond the restricted concept of nosological diagnoses. It involves a multilevel formulation of health status (both ill and positive aspects of health) through interactive participation and engagement of clinicians, patients, and families using all relevant descriptive tools (categorization, dimensions, and narratives). The current organizational schema of the PID comprises a multilevel standardized component model integrating three main domains. Each level or major domain addresses both ill health and positive aspects of health. The first level is the assessment of health status (ill health and positive aspects of health or well-being). The second level includes contributors to health, both risk factors and protective factors. The third major level includes health experience and values. Experience with the PID through a practical guide in Latin America supported the usefulness and adequacy of the PID model.

Keywords: person-centered medicine, Person-Centered Integrative Diagnosis Model, health status, contributors to health, narratives, positive aspects of health, well-being

Corresponding Address: Professor \& Inaugural Chair, Department of Neuroscience Director, Institute for Neuroscience School of Medicine HCEBL-Ste. 2.136.26 2102 Treasure Hills Blvd Harlingen, TX 78550, USA

E-mail: ihsan.salloum@utrgv.edu

\footnotetext{
${ }^{a}$ Board Director, International College of Person Centered Medicine; Professor \& Inaugural Chair, Department of Neuroscience, Director, Institute for Neuroscience University of Texas Rio Grande Valley School of Medicine; Chair, Section on Classification, Diagnostic Assessment \& Nomenclature; Emeritus Professor of Psychiatry, University of Miami Miller School of Medicine.

${ }^{b}$ Professor of Psychiatry, Icahn School of Medicine at Mount Sinai, New York; Secretary General and Former President, International College of Person Centered Medicine; Council Member and Former President, World Psychiatric Association
} 


\section{INTRODUCTION}

Person-centered medicine (PCM) embraces holistic concepts of health advocating the whole person in context as the center and goal of clinical care and public health [1]. PCM strives toward a personalized approach to care within an integrated biological, psychological, social, and cultural framework. Ancient traditions as well as modern concepts of care highlight the holistic concept of health [2-9]. This is also reflected in the World Health Organization's definition of health as not merely the absence of disease but a state of "complete physical, emotional, and social well-being" [10].

The overarching principles of PCM gleaned from a reiterative process involving comprehensive literature reviews, focus groups, and international expert consensus [11] include the following:

1. Ethical Commitment, which refers to respect for the dignity of every person involved in the care process (patients, family, clinicians), respect for the patient's rights, promoting the patient's autonomy and empowerment, paying attention to the patient's personal values, choices, and needs, and the fulfillment of the patient's life project.

2. Cultural Sensitivity "this refers to cultural Awareness and responsiveness," of "being attentive to the patient's ethnic identity, cultural values, spiritual needs, language, communication needs and preferences, and the patient's gender identity and sexual needs."

3. Holistic Approach with a bio-psycho-socio-cultural-spiritual framework and equal attention to both ill health (diseases, disabilities) and positive health or well-being (functioning, resilience, resources, and quality of life).

4. Relational Focus, establishing therapeutic alliance and cultivating the clinician-patient relationship, displaying empathy in the care process, and establishing trust during clinical communication and care.

5. Individualization of Care with focus on the patient's uniqueness, promoting the patient's personal growth and development, considering the patient's personal choices in life and social context.

6. Shared Understanding and Shared Decision-making promoting shared understanding of patient's health situation, conducting a diagnosis of health (rather than just ill health) and shared decision making for treatment planning and the care process.

7. People-Centered Organization of Services including advocacy for the health and rights of all people in the community, people's participation in the planning of health services, promoting partnership at all levels of service organization, promoting quality and excellence in personalized services, 
service responsiveness to community needs and expectations, and integration and coordination of services around patients' needs. It also includes emphasis on people-centered primary care services to ensure continuity of care, and services informed by international perspectives and developments for personcentered care.

8. Person-Centered Education, Training and Research with a health system committed to promoting person-centered public health education, personcentered health professional training, and person-centered clinical research.

The process of diagnosis is central to health care practices and to implementing the goals and principles of care. However, traditional diagnostic approaches are focused almost entirely on identifying ill health and have paid limited attention to the totality of health, with scant consideration of positive aspects of health.

The Person-Centered Integrative Diagnosis model (PID) is a key diagnostic tool of person-centered medicine. It operationalizes principles of medicine for the person into an integrated individualized diagnostic model applicable to regular clinical care [12]. The development of this model initiated under the auspices of the World Psychiatric Association's Institutional Program on Psychiatry for the Person (WPA General Assembly, 2005). The PID embodies the principles of PCM and their application in regular clinical care and is adaptable to the diverse clinical realities and needs. Importantly, it is measurable, employing categorical, dimensional and narrative approaches allowing for quantitative, qualitative, and mixed analysis to assess the impact of the application of this model on the processes of care as well as on patients' outcome.

Thus, the PID aims at putting into practice the vision of person-centered medicine affirming the whole person of the patient in context as the center of clinical care and health promotion at the individual and community levels. The purposes of the Person-Centered Integrative Diagnosis (PID) model are to provide a diagnosis of health status (ill \& positive health), to serve as informational bases for clinical care and public health, to enhance clinical care and outcome, to promote recovery and health restoration, and to promote prevention and health promotion. Thus, the PID is viewed to be a diagnostic model of the person (of the totality of the person's health, ill, and positive), by the person (including clinicians considered as full human beings and not merely "undescript technicians"), for the person (for the fulfillment of the person's health \& life project), and with the person (in a respectful and empowering relationship).

In the following section we discuss key paradigm shifts introduced by the Person-Centered Diagnostic Model (PID), and will present its structure as an integrated, personalized, multilevel assessment of health status. 


\section{KEY PARADIGM SHIFTS OF THE PERSON-CENTERED INTEGRATIVE DIAGNOSIS (PID) MODEL}

The first key paradigm shift involves the essential notion of diagnosis. The PID broadens the traditional notion of "diagnosis" from a restrictive nosological understanding to a broader and deeper notion of diagnosis to include the totality of health encompassing both its positive and ill aspects. This encompassing notion of diagnosis is in concordance with the WHO's 1946 visionary definition of health mentioned earlier and it is well captured by the 20th-century Spanish philosopher and humanist, Ortega y Gasset' (1883-1955) statement "I am I and my circumstance" [13], which embodies the PCM and PID's vision of considering "the whole person in context" as the center and goal of clinical care and public health. Furthermore, the PID promotes a notion of diagnosis as a process involving the interactive participation and engagement of clinicians, patients, and families, leading to the formulation and articulation of the patient's health in its totality.

The primary role of diagnosis in medicine as the basic unit in the process of medical care is indicated by its multiple functions. Diagnosis is essential for communication among health professionals and other stakeholders, it is central for the process of clinical care and the identification and treatment of disorders, it is important for prevention and health promotion, and it is necessary for conducting research, testing interventions and understanding disease mechanisms. Furthermore, diagnosis is needed for education and training and for a host of administrative purposes from quality improvement to reimbursement activities. Feinstein [14] cogently expressed the pivotal role of diagnosis in the clinicians' work "Diagnostic categories provide the locations where clinicians store the observations of clinical experience" and "The diagnostic taxonomy establishes the patterns, according to which clinicians observe, think, remember and act."

The PID's broader notion of diagnosis with the focus on the totality of health and on giving substantial attention to positive aspects of health as well as diagnosis as an interactive process helps to enhance the positive connotations associated with diagnosis. These include increased understanding and empowerment. This approach also contributes to mitigating negative connotations such as pejorative value judgments, stigma, and labeling associated with certain diagnosis (e.g., psychiatric conditions).

The second key feature of the PID is its partnership approach with an emphasis on an inclusive and collaborative process. All stakeholders in the clinical encounter are empowered as protagonists of the diagnostic process. The diagnostic formulation is an ongoing process, constructed through interactive partnership involving a dialogue among the primary stakeholders and evaluators. The PID upholds the dignity, values, and aspirations of the person seeking care through a 
partnership of equals that includes the clinician (the conventional expert), the patient (the protagonist, informationally and ethically), the family (crucial support group), and community members (teachers, social workers, etc.). This partnership approach enhances self-efficacy, which has been found to mediate positive health and healing [15].

The third paradigm shift is the inclusion of narrative and subjective experience into the diagnostic model. The narrative reflects the uniqueness of the person's health experience as well as other stakeholders' subjective experience into the diagnostic process. The narrative corresponds to the idiographic personalized content that captures the experience of illness. This includes topics such as suffering, values, meaning of illness, expectation of health, and the cultural experience of illness and care. It also includes the experience of well-being such as personal belonging and uniqueness as well as cultural identity. Beliefs about health and illness are crucial for self-care and may influence behavioral and physiological responses to illness [16-17].

\section{THE MULTILEVEL SCHEME OF THE PERSON-CENTERED INTEGRATIVE DIAGNOSIS MODEL}

The initial development of the PID model was anchored within the wellestablished experience of the World Psychiatric Association in the development of diagnostic models and contributions to the central issue of international diagnoses in psychiatry [18-21]. The current organizational schema of the PID comprises a multilevel standardized component model integrating three main domains. Each level or major domain addresses both ill health and positive aspects of health [21].

The first major level is the assessment of the health status (ill health and positive aspects of health or well-being), the second major level includes contributors to the health status. These are contributors to ill health and contributors to well-being. The third major level includes health experiences and values (of ill health and of well-being). Each of these levels is further organized into key domains. See Figure 1 corresponding to the Diagnostic Formulation of the Latin American Guide for Psychiatric Diagnosis, Revised Version (GLADP-VR) [22, 23].

The health status levels document the illness and its burden. Disorders, as classified in the WHO International Classification of Diseases, Revision 10 (ICD10), are documented under this domain. Functioning (or disabilities) is also considered under these domains. Overall functioning, as well as major areas of functioning related to personal care, occupational functioning, functioning with family, and social functioning are considered and rated on a 0 to 10 Likert scale, as is done for well-being. A narrative component complements the assessment of 
Name: Code: Date:

Age: Sex: M/F Marital Status: Occupation:

\section{HEALTH STATUS}

Clinical Disorders and Related Conditions (as classified in CIE-10).

A. Mental Disorders (in general, including personality and developmental disorders, and related conditions):

\begin{tabular}{|l|l|}
\hline & Codes: \\
\hline & \\
\hline
\end{tabular}

B. General Medical Conditions:

\begin{tabular}{|l|l|}
\hline & Codes: \\
\hline & \\
\hline
\end{tabular}

Functioning of the Person (Use the following scale to evaluate each of the functioning areas)

\begin{tabular}{llcccccccr} 
Poorest & Minimal & & Marginal & & Acceptable & Substantial & Excellent \\
\hline 0 & 1 & 2 & 3 & 4 & 5 & 6 & 7 & 8 & 9
\end{tabular}

\begin{tabular}{|l|l|l|l|l|l|l|l|l|}
\hline \multicolumn{2}{|l|}{ Functioning Areas } & \multicolumn{7}{|c|}{ Score } \\
\hline A & Personal care & 0 & 2 & 4 & 6 & 8 & 10 & $?$ \\
\hline B & Occupational (wage earner, student, etc.) & 0 & 2 & 4 & 6 & 8 & 10 & $?$ \\
\hline C & With family & 0 & 2 & 4 & 6 & 8 & 10 & $?$ \\
\hline D & Social in general & 0 & 2 & 4 & 6 & 8 & 10 & $?$ \\
\hline
\end{tabular}

Degree of Well-being (Indicate level perceived by the person on the following scale, optionally using a suitable instrument).

\begin{tabular}{llllllllllr} 
Poorest & \multicolumn{1}{l}{10} & Excellent \\
\hline 0 & 1 & 2 & 3 & 4 & 5 & 6 & 7 & 8 & 9 & 10
\end{tabular}

\section{HEALTH CONTRIBUTING FACTORS}

Risk Factors: [] Abnormal weight [] Hyper-cholesterolemia [] Hyperglicemia [] Hypertensión [] Tabacco [] Alcohol [] Family psychiatric problems [] Severe child trauma [] Prolongued or severe stress

Additional information:

Protective Factors: [] Healthy diet [] Physical activity [] Creative activities [] Social participation Additional information:

\section{HEALTH EXPERIENCES AND EXPECTATIONS}

Personal and cultural identity:

Suffering (its recognition, idioms of distress, illness beliefs):

Experiences and expectations on health care:

Figure 1. GLADP-VR Personalized Diagnostic Formulation Form 
this level, where patients and clinicians can provide a narrative, personalized account of this level of assessment.

The contributors to health level addresses both intrinsic and extrinsic contributors to the health status utilizing a bio-psycho-social framework. This level also documents specific contributors to ill health derived from the World Health Professions Alliance health improvement cards [24]. Specifically listed health promoters include diet, physical activity, creative activity, social involvement, and others. Specific health risk includes overweight, high lipid, high glucose, high blood pressure, alcohol and tobacco use, family history, early life trauma, significant stress, and others. This level also includes a narrative component.

The third level corresponds to the idiographic personalized narrative capturing health experience and values. It includes experience of well-being including personal values and cultural identity and experience of ill health to include suffering, meaning of illness, values, and cultural experience of illness and care and expectation of health care.

The PID schema and its GLADP-VR practical application are aimed at forming the informational bases for intervention and care, such as developing treatment plans to guide recovery and health restoration, as well as to providing the informational bases for education, public health planning and for administrative functions.

The PID avails all relevant descriptive tools, including categorical, dimensional, and narrative approaches. These approaches allow for capturing quantitative and categorical assignments above a certain threshold. The use of narrative offers the possibility of a deeper and richer personalized description of a relevant domain.

The PID model was officially adopted by the Latin American Guide to Psychiatric Diagnosis (GLADP-VR) [23], through which significant experience was gained in the application of the PID in regular patient care. Experience with the GLADP documented the effectiveness of the PID model in providing a personalized diagnostic formulation and in addressing cultural issues [25].

\section{CONCLUSIONS}

The person-centered integrative diagnosis (PID) aims at putting into practice the vision of person-centered medicine affirming the whole person of the patient in context as the center of clinical care and health promotion at individual and community levels. The PID is a novel model of conceptualizing the process and formulation of clinical diagnosis. The PID presents several paradigm shifts with a broader and deeper notion of diagnosis of the whole of health, beyond the more restricted conceptualization of nosological diagnoses. It involves a multilevel formulation of health (both ill and positive aspects of health), arrived at through 
interactive participation and engagement of clinicians, patients, and families using various relevant descriptive tools (categorization, dimensions, and narratives). Extensive experience with the PID model through its GLADP-VR practical application demonstrated its utility and practicality of use within regular clinical care in providing a personalized and culturally informative diagnosis within a partnership framework that actively engages the patient into the diagnostic and care process.

\section{ACKNOWLEDGMENTS AND DISCLOSURES}

The authors do not report any conflicts of interest.

\section{REFERENCES}

1. Mezzich JE. 2007. Psychiatry for the Person: Articulating Medicine's Science and Humanism. World Psychiatry 6 (2): 1-3.

2. Herrman H, Saxena S, Moodie R. 2005. Promoting Mental Health: Concepts, Emerging Evidence, Practice, WHO, Geneva.

3. World Health Organization. 1999.WHO's New Global Strategies for Mental Health. Factsheet 217.

4. U.S. Presidential Commission on Mental Health. 2003. Achieving the Promise: Transforming Mental Health Care in America. Final Report. DHHS Pub N: SMA-03-3832. Rockville, Maryland: Department of Health and Human Services.

5. World Health Organization European Ministerial Conference on Mental Health. Mental Health Action Plan for Europe: Facing the Challenges, Building Solutions. Helsinki, Finland, January 12-15, 2005. EUR/04/5047810/7.

6. Patwardhan B, Warude D, Pushpangadan P, Bhatt N. 2005. Ayurveda and Traditional Chinese Medicine: A Comparative Overview. Evidence-Based Complementary and Alternative Medicine 2: 465-473.

7. Christodoulou GN. (Ed) 1987. Psychosomatic Medicine, Plenum Press, New York.

8. Anthony W. 1993. Recovery from Mental Illness. The Guiding Vision of the Mental Health Service Systems in the 1990s. Psychosocial Rehabilitation Journal 16: 11-23.

9. Amering M, Schmolke M. 2007. Recovery - Das Ende der Unheilbarkeit, Psychiatrie-Verlag, Bonn.

10. World Health Organization. 1946. WHO Constitution, WHO, Geneva.

11. Mezzich JE, Kirisci L, Salloum IM, Trivedi JK, Kar SK, Adams N, Wallcraft J. 2016. Systematic Conceptualization of Person Centered Medicine and Development and Validation of a Measurement Index. International Journal of Person Centered Medicine 6 (4): 219-247. 
12. Mezzich JE, Salloum IM. 2009. Towards a Person-Centered Integrative Diagnosis. In: IM Salloum \& JE Mezzich (Eds). Psychiatric Diagnosis: Context and Prospects, Wiley-Blackwell, Oxford, UK, pp. 297-302.

13. Lain-Entralgo P. 1982. El Diagnostico Medico: Historia y Teoría, Salvat, Barcelona.

14. Feinstein AR. 1967. Clinical Judgment, Robert E. Krieger, Huntington, NY.

15. Mezzich JE. This issue. Setting a Common Ground for Collaborative Care and Clinical Interviewing: International Journal of Person Centered Medicine 8(3): 29-40.

16. Kirmayer L, Mezzich JE, Van Staden W. 2016. Health Experience and Values. In: JE Mezzich, M Botbol, GN Christodoulou, CR Cloninger, \& Salloum IM (Eds). Person Centered Psychiatry, Springer, Switzerland, pp. 179-199.

17. Mezzich JE. 2012. Towards a Health Experience Formulation for PersonCentered Integrative Diagnosis. International Journal of Person Centered Medicine 2: 188-192.

18. Mezzich JE, Ustun TB. 2002. International Classification and Diagnosis: Critical Experience and Future Directions. Psychopathology 35 (Special Issue): 55-202.

19. Banzato CEM, Mezzich JE, Berganza CE. (Eds) 2005. Philosophical and Methodological Foundations of Psychiatric Diagnosis. Psychopathology 38 (Special Issue Jul-Aug).

20. World Psychiatric Association. 2003. Essentials of the World Psychiatric Association's International Guidelines for Diagnostic Assessment (IGDA). British Journal of Psychiatry 182 (Suppl 45): s37-s66.

21. Mezzich JE, Salloum IM, Cloninger CR, Salvador-Carulla L, Kirmayer L, Banzato CE, Wallcraft J, Botbol M. 2010. Person-Centered Integrative Diagnosis: Conceptual Bases and Structural Model. Canadian Journal of Psychiatry 55: 701-708.

22. Mezzich JE, Otero A, Saavedra JE, Salloum IM. 2013. The GLADP-VR Person-Centered Diagnostic Formulation: Background, Concepts, and Structure. International Journal of Person Centered Medicine 3: 228-242.

23. Asociación Psiquiátrica de América Latina (APAL). 2012. Guia Latinoamericana de Diagnostico Psiquiátrico, Versión Revisada (GLADP-VR) (Latin American Guide of Psychiatric Diagnosis, Revised Version). Lima: APAL.

24. WHPA Health Improvement Card: https://www.whpa.org/sites/default/ files/2018-12/ncd_Health-Improvement-Card_web.pdf

25. Saavedra JE, Otero A, Brítez J, Velásquez E, Salloum IM, Zevallos S, Luna Y, Paz V, Mezzich JE. 2017. Evaluation of the Applicability and Usefulness of the Latin American Guide for Psychiatric Diagnosis, Revised Version, in Comparison with Other International Systems among Latin American Psychiatrists. International Journal of Person Centered Medicine7: 216-224. 